\title{
Identifying inequitable exposure to toxic air pollution in racialized and low-income neighbourhoods to support pollution prevention
}

\author{
Suzanne $\operatorname{Kershaw}^{1}$, Stephanie Gower ${ }^{2,3}$, Claus Rinner ${ }^{1}$, Monica Campbel12,3 \\ ${ }^{1}$ Department of Geography, Ryerson University, Toronto, Canada; ${ }^{2}$ Healthy Public Policy Directorate, Toronto \\ Public Health, Toronto, Canada; ${ }^{3}$ Dalla Lana School of Public Health, University of Toronto, Toronto, Canada
}

\begin{abstract}
Numerous environmental justice studies have confirmed a relationship between population characteristics such as low-income or minority status and the location of environmental health hazards. However, studies of the health risks from exposure to harmful substances often do not consider their toxicological characteristics. We used two different methods, the unit-hazard and the distance-based approach, to evaluate demographic and socio-economic characteristics of the population residing near industrial facilities in the City of Toronto, Canada. In addition to the mass of air emissions obtained from the national pollutant release inventory (NPRI), we also considered their toxicity using toxic equivalency potential (TEP) scores. Results from the unit-hazard approach indicate no significant difference in the proportion of low-income individuals living in host versus non-host census tracts $(\mathrm{t}(107)=0.3, \mathrm{P}=0.735)$. However, using the distance-based approach, the proportion of low-income individuals was significantly higher $(+5.1 \%, \mathrm{t}(522)=6.0, \mathrm{P}<0.001)$ in host tracts, while the indicator for "racialized" communities ("visible minority") was $16.1 \%$ greater $(\mathrm{t}(521)=7.2, \mathrm{P}<0.001$ ) within $2 \mathrm{~km}$ of a NPRI facility. When the most toxic facilities by non-carcinogenic TEP score were selected, the rate of visible minorities living near the most toxic NPRI facilities was significantly higher $(+12.9 \%, \mathrm{t}(352)=3.5, \mathrm{P}=0.001)$ than near all other NPRI facilities. TEP scores were also used to identify areas in Toronto that face a double burden of poverty and air toxics exposure in order to prioritise pollution prevention.
\end{abstract}

Keywords: air pollution, toxic equivalency potential, national pollutant release inventory, environmental justice, spatial analysis, Canada.

\section{Introduction}

Extensive research confirms that an individual's health is affected by the social, biophysical and economic conditions of the places in which he or she is born, grows, lives, works and ages (e.g. Raphael, 2004; Marmot and Wilkinson, 2006; CSDH, 2008). In particular, social and economic conditions of a population or an individual determine their risk of becoming ill and their ability to prevent or treat health problems. Research conducted in Canada and elsewhere consistently suggests that lower-income and minority groups face significant inequalities in health status (e.g. Lille-Blanton, 1996; Nazroo, 2003; Toronto Public Health, 2008). This is often viewed as arising from overlapping hardships that result from injustice (Wakefield and Baxter, 2010). This perspective of

\footnotetext{
Corresponding author:

Claus Rinner

Department of Geography

Ryerson University

350 Victoria Street, Toronto, ON, M5B 2K3, Canada

Tel./Fax +1 4169795000 ext. 2686

E-mail: crinner@ryerson.ca
}

"compounded disadvantage" demonstrates direct linkages between environment and human health, raising issues of social injustice.

One of the factors that could contribute to poorer health in some population groups is inequitable exposure to environmental hazards such as industrial air pollution. Industrial facilities contribute to the complex mix of air pollution in cities that can adversely affect the health of residents. Their emissions include common air contaminants such as particulate matter, nitrogen oxides and ozone that are linked to cardiovascular and respiratory effects, including reduced lung function, asthma and chronic obstructive pulmonary disorder (Dockery et al., 1993; Schwartz, 1994; Samet et al., 2000; Brunekreef and Holgate, 2002; Pope et al., 2002; Samet and Krewski, 2007). Industrial facilities also emit air toxics, long-term exposure to which is associated with development of cancer or other serious conditions such as reproductive effects or birth defects (Caldwell et al., 1998; Cohen, 2000; US Environmental Protection Agency, 2012). Examples of air toxics include benzene, perchlorethlyene and lead.

Indeed much of the existing environmental justice research suggests that the likelihood of living close to 
an industrial polluter falls disproportionately on minority and economically deprived communities. Benjamin and Lee (1987) found that across the United States of America (USA), poor and minority residents disproportionately occupied zip codes with commercial hazardous waste facilities. A 1994 update to the study found that the disparities had worsened, and that the chance of non-whites residing near landfills was $47 \%$ greater than for whites (Goldman and Fitton, 1994). Since then, a number of studies focused on populations living near pollution sources have reported similar findings (Chakraborty and Armstrong, 1997; Daniels and Friedman, 1999; Allen, 2001; Pastor et al., 2005; Abel, 2008).

Some research has gone a step further to explore whether there is a correlation between the degree of hazard posed by a facility and the likelihood of finding minority and low-income populations living nearby. Such efforts acknowledge that some polluters pose relatively greater risks to nearby populations than others because they emit either larger quantities of pollutants, or they emit pollutants that are more toxic. Sicotte (2010) assigned hazard points to Philadelphia facilities and found that hazard burdens tended to be concentrated in areas with more minority residents, more vacant housing units, and more adults without a high-school diploma. Hipp and Lakon (2010) found that in six Southern California (USA) census tracts, those with more Latinos and Asians were more likely to be exposed to toxic waste, while those with a high proportion of residents with post-secondary education were less likely to be exposed. The effects were stronger when weights were applied to account for toxicity of the waste. However, in another study the relationship between the hazard ranking of a toxic release inventory facility and a neighbourhood's socio-economic status was not significant (Neumann et al., 1998).

Others have used information about the degree of hazard posed by facility emissions to identify neighbourhoods experiencing a "double burden" of both disproportionate levels of toxic emissions and disproportionate levels of poverty. Abel (2008) and Ash et al. (2009) used risk-screening environmental indicators (RSEI) to identify minority and low-income neighbourhoods subject to the most toxic emissions in metropolitan St. Louis (Missouri) and across the USA, respectively. Both analyses demonstrated environmental injustice arising from exposure to industrial emissions, and identified specific communities that experience the double burden of disproportionate levels of toxic emissions coupled with high poverty and/or predominance of minority populations.

Much of the existing environmental justice research originates in the USA. It is not clear whether American findings about the links between race, socio-economic status and proximity to industrial or hazardous sites are likely to translate directly to the Canadian context (Nnorom, 2011) or other societies world-wide. In contrast to Americans, Canadians benefit from universal health care and social programming based on progressive taxation (Buzzelli, 2008), which could reduce disparities in access to health services and social supports. Others argue that the racial "ghettoization" seen in many US cities is not occurring in Canada, but that income-based segregation may be more relevant (e.g. Walks and Bourne, 2006).

While some Canadian research suggests that inequities may exist in terms of exposure to ambient air pollution (Buzzelli and Jerrett, 2004; Crouse et al., 2009), there is little information characterising the populations living in proximity to industrial polluters in Canada. One such study identified 17 neighbourhoods within the City of Toronto, Canada that had both a high mass of air emissions and a poverty rate above the national average of $11.8 \%$, but the authors did not consider the toxicity of emissions (Rang et al., 2008). We review their findings considering both the mass and toxicity of emissions in order to provide a more complete understanding of the double burden of environmental hazard and socio-economic marginalisation across Toronto neighbourhoods.

Despite the recognition that air pollution poses a health risk to residents of Toronto, to date, there has been limited investigation of whether persons with low socio-economic or minority status are differentially exposed to air pollution based on where they live. As in other major cities, gentrification (socio-economic neighbourhood change) in Toronto has forced many low-income households to settle in, or move to, less advantaged communities (Filion, 1991). Although it is reasonable to expect that these communities are located closer to industrial areas of the city, there is no known analysis of where populations may be exposed to particularly toxic emissions. This information would aid in prioritising pollution prevention strategies across the city, enabling areas of greatest toxicity and greatest disparity to be targeted first.

The objective of this research is to inform prioritysetting for pollution prevention by characterising neighbourhoods near large industrial air polluters. We aim to identify: (i) which Toronto neighbourhoods may be exposed to the most harmful airborne industrial emissions, when both mass and toxicity of 
emissions are considered; (ii) whether these neighbourhoods are more likely to be characterised by populations who are already at risk of unequal health outcomes due to "racialization" or socio-economic disadvantage; and (iii) where toxic emissions and racial or socio-economic disadvantages converge spatially.

\section{Materials and methods}

\section{Study area}

The study was carried out in the City of Toronto, the centre of Canada's largest metropolitan region and one of Canada's most ethnically diverse cities, with over half of residents born in another country, and over 140 languages and dialects spoken. In Toronto, the common air contaminants contribute to approximately 1,700 premature deaths and 6,000 hospitalizations each year (Toronto Public Health, 2004). While the burden of illness from toxic air contaminants is unknown, reviews of local data suggest that air toxics are likely to be present in Toronto's air at levels that pose a risk to health (Toronto Public Health, 2002, 2008).

\section{Facility locations and emissions data}

The national pollutant release inventory (NPRI) was established by the Government of Canada in 1992 for the purpose of recording substance releases and transfers to air, water and land, as well as disposals and offsite transfers for recycling from large industrial, commercial, institutional and public works facilities across Canada on an annual basis (Environment Canada, 2010). Facilities with 10 or more full-time employees and/or who are subject to reporting requirements have to report to the NPRI (Environment Canada, 2009). In 2007, facilities were required to report on 347 substances.

Facilities located within the City of Toronto and reporting emissions to the NPRI in 2007 were geocoded by address in ArcMap version 9.2 (ESRI, Redlands, CA, USA). The dataset only included records classified as "facility address", not those containing the "parent company address", "technical contact address" or "public contact address". These data were verified using Google Maps to ensure that facilities located on large plots of land were accurately represented. For each facility, the list of substances reported and the mass of annual emissions in 2007 was retained.

\section{Demographic and socio-economic variables}

Several indicators from the 2006 Canadian Census were selected to characterise demographic and socioeconomic status in the City of Toronto at the census tract level (see Table 1). These variables were selected because they encompass a range of social and economic indicators relating to minority status, income, dwelling tenure, education and employment status. Many of these indicators have been used in other environmental justice and inequality studies (e.g. Daniels and Friedman, 1999; Mohai and Saha, 2006; Kearney and Kiros, 2009). Using them here may facilitate cross-jurisdictional comparison of results.

\section{Spatial assessment of air pollution}

Point density tools can be used to create a continuous surface that represents the density of a set of input features. Densities can be calculated using simple or kernel density functions. Kernel density estimation creates a composite density surface, which results in a smoother distribution of values than simple point density (Fotheringham et al., 2000). Kernel density estimation has been used in numerous studies to model spatial processes (e.g. Corcoran et al., 2007; Wing and Tynon, 2006; Anderson, 2009). The density of NPRI facilities in the City of Toronto was assessed using the quadratic kernel density function in ArcMap. The radius used in the kernel density function was defined as $1 \mathrm{~km}$. Density values were translated into three-dimensional (3D) surfaces for enhanced visualization.

Two alternative approaches were used to assign emissions to areal units and distinguish populations that are potentially affected by NPRI facilities from those that are not. The first method is the unit-hazard approach, where census tracts containing one or more NPRI facilities were identified as host units through point-in-polygon overlay (Fig. 1a) in ArcGIS. The second is the distance-based approach with the centroid containment method. Buffers of $1 \mathrm{~km}$ and $2 \mathrm{~km}$ radii, respectively, were drawn around the NPRI facilities in ArcGIS. The "select by location" function was used to identify the census tracts whose centroids were located inside each buffer and define them as host tracts (Fig. 1b). These two distances were chosen to correspond to those used in environmental justice studies conducted in the USA (Neumann et al., 1998; Abel 2008; Kearney and Kiros, 2009) and to approximate the dimensions of Toronto census tracts (average area $\left.=1.2 \mathrm{~km}^{2}\right)$. 
Table 1. Census variables used to represent demographic and socio-economic population characteristics.

\begin{tabular}{|c|c|}
\hline Variable & Description \\
\hline \multicolumn{2}{|l|}{ Ethnicity/ immigration/ language } \\
\hline Visible minority $^{\mathrm{a}}$ & $\%$ of population who identified as a "visible minority" \\
\hline Chinese & $\%$ of population who identified as "Chinese" \\
\hline South Asian & $\%$ of population who identified as "South Asian" \\
\hline Black & $\%$ of population who identified as "Black" \\
\hline Filipino & $\%$ of population who identified as "Filipino" \\
\hline White & $\%$ of population who identified as "not a visible minority" \\
\hline Recent immigrant & $\%$ immigrated between 2001 and 2006 \\
\hline Not speaking English & $\%$ persons not speaking English \\
\hline \multicolumn{2}{|l|}{ Income/education } \\
\hline Low income persons ${ }^{b}$ & $\%$ persons below after-tax low income cut-off (2005) \\
\hline Low educational attainment & $\%$ adults (aged $\geq 25$ years) without a high school education \\
\hline \multicolumn{2}{|l|}{ Home ownership } \\
\hline Rented dwellings & $\%$ of occupied private dwellings that are rented \\
\hline \multicolumn{2}{|l|}{ Higher-risk populations } \\
\hline Children & $\%$ of population aged $<15$ years \\
\hline Seniors & $\%$ of population aged $\geq 65$ years \\
\hline \multicolumn{2}{|l|}{ Employment } \\
\hline Unemployed & $\%$ of population (aged $\geq 15$ years) in the labour force that are unemployed \\
\hline Management occupation & $\%$ of labour force (aged $\geq 15$ years) with management occupation \\
\hline Business/administrative occupation & $\%$ of labour force (aged $\geq 15$ years) with business/administrative occupation \\
\hline Trade occupation & $\%$ of labour force (aged $\geq 15$ years) with trade occupation \\
\hline Sales occupation & $\%$ of labour force (aged $\geq 15$ years) with sales occupation \\
\hline
\end{tabular}

"The term "visible minority" has been criticised as discriminatory (United Nations Committee on the Elimination of Racial Discrimination, 2007), and inadequate given the different levels of education, work experience, degrees of assimilation and discrimination in the Canadian labour market (Hum and Simpson, 2000). However, the variable "visible minorities" - defined as 'persons, other than Aboriginal peoples, who are non-Caucasian in race or non-white in colour' (Statistics Canada, 2010) - is considered a valid tool for studying aspects of race-based inequities (Bauder, 2001) and may be the best data available for Toronto. As many agencies prefer the concept of racialization ("the process by which societies construct races as real, different, and unequal in ways that matter to economic, political and social life" (Commission on Systemic Racism in the Ontario Criminal Justice System, 1995)), we use the terms visible minority and racialized community interchangeably in the remainder of this paper.

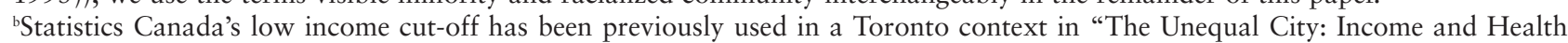
Inequalities in Toronto" (Toronto Public Health, 2008).

\section{Quantifying emissions using mass and toxicity}

The relative human health risk from NPRI emissions in Toronto was characterised using the toxic equivalency potential (TEP) scoring system. TEP scores are used by a number of organisations both in North America (Scorecard, Commission for Environmental Cooperation [CEC]) and internationally, e.g. the Queensland Environmental Protection Agency in Australia) and address the fact that the health risk posed by identical quantities of two different chemicals can vary substantially based on their respective toxicities and potential for human exposure (McKone, 1993; US Environmental Protection Agency, 1997;
Hertwich et al., 2001; Pennington and Bare, 2001). A chemical's TEP is the ratio of risk posed by a onepound release of the substance relative to the risk posed by a one-pound release of a reference chemical. For carcinogens, the reference chemical is benzene; for non-carcinogens, it is toluene. TEPs can then be multiplied by the mass of a chemical release, which results in a unit-less TEP score, allowing emissions of individual substances to be characterised and compared in terms of their risk to human health.

TEP scores for multiple releases can be summed to arrive at a single TEP score for a source with emissions of more than one substance. This enables facilities with multiple emissions to be compared with one 


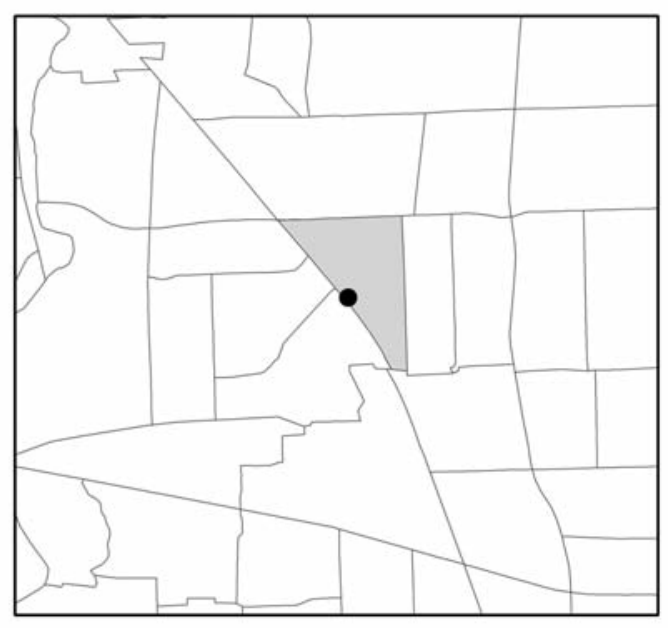

a) Unit-hazard approach

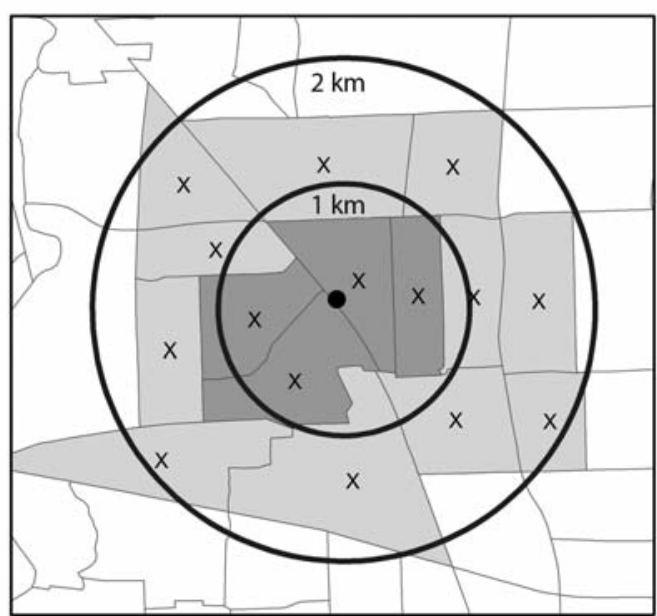

b) Distance-based approach (centroid containment)

Fig. 1. (a) The unit-hazard approach selects only census tracts that contain an NPRI facility; (b) The distance-based approach selects census tracts whose centroid is within a specified distance of an NPRI facility.

another in terms of their risk to human health. When summing TEP scores for sources with multiple emissions, carcinogen and non-carcinogen TEP scores are kept separate. This reflects classical health risk assessment practice (National Research Council, 1994) and an appreciation that different modes of action may underlie development of cancer and non-cancer health outcomes. While non-carcinogens are considered "safe" below specific exposure thresholds, carcinogens are thought to pose a risk at any level of exposure. For the present research, the emissions from each Toronto facility were characterised in terms of the mass of annual emissions; TEP score of annual carcinogenic emissions; and TEP score of annual non-carcinogenic emissions.

Derived from facility locations and facility-specific emissions, each Toronto census tract was then characterised in terms of: (i) presence and density of facilities; (ii) total mass of annual emissions summed across its facilities per $\mathrm{km}^{2}$; (iii) TEP score of annual carcinogenic emissions summed across its facilities per $\mathrm{km}^{2}$; and (iv) TEP score of annual non-carcinogenic emissions summed across its facilities per $\mathrm{km}^{2}$. Facilities and census tracts were then ranked according to each set of scores.

\section{Analysis procedure}

The analysis was conducted in four stages. Firstly, the spatial patterns of airborne industrial emissions in Toronto were visually assessed according to the above four measures: location of facilities, mass of emissions, and TEP scores for carcinogenic and non-carcinogenic substances. Kernel densities were mapped using 3D representation. The unit-hazard approach was then used to aggregate and map TEP scores by census tracts in order to avoid double-counting of facilities located near multiple census tracts. Secondly, socio-economic characteristics of host tracts were compared to nonhost tracts using a $t$-test on mean values and host tract definitions according to the two spatial assessment approaches. For variables with skewed distributions, the $t$-tests were calculated after square-root transformation. Thirdly, the population characteristics of census tracts in proximity to the greatest emitters were compared to those of all other host tracts. For this stage, the 10 greatest emitters were defined separately by mass, carcinogen TEP score and non-carcinogen TEP score. And fourthly, census tracts that suffer a double burden of potential pollution exposure and racial or socio-economic disadvantage were identified. The double burden was defined by proximity to the ten most toxic facilities as well as the quintiles of census tracts with the largest proportions of minority and low-income populations.

\section{Results}

\section{Spatial distribution of air pollution in Toronto}

In Toronto, 233 facilities reported air releases to the NPRI in 2007. The total reported annual pollutant mass by facility ranged between 0.00001 and 896.4 tonnes (median $=7.5$ tonnes). Thirty-nine facilities emitted carcinogens, with facility-specific carcinogen TEP scores ranging from 0.00003 to 345.6 (median = 
0.8), while 225 facilities emitted non-carcinogens, with facility-specific non-carcinogen TEP scores ranging from 0.009 to 67056.0 (median $=24.7$ ).

The 3D maps in Fig. 2 show the kernel density estimation for facility count, mass of emissions and toxicity of emissions. Facility count (Fig. 2a) and mass of emissions (Fig. 2b) show markedly different spatial patterns than toxicity measured by the density of carcinogen (Fig. 2c) and non-carcinogen (Fig. 2d) TEP scores. By facility count, density peaks are located in the downtown core and in the northwest area of Toronto. When mass of emissions is considered, the highest peaks are in the northwest and southwest parts of the city. In contrast, TEP score densities for carcinogenic and non-carcinogenic substances are highest to the east of the Don Valley Parkway, while densities in the western part of Toronto are close to zero.
Comparing census tracts by quantity and toxicity of emissions

Fig. 3 shows emissions data aggregated to the census tract level under four different criteria: (i) facility density; (ii) mass of emissions; (iii) carcinogen TEP score; and (iv) non-carcinogen TEP score. The top ten census tracts in each category are also highlighted. There are 72 census tracts $(13.6 \%)$ in Toronto that have at least one NPRI facility. Among these, the density of facilities averages 1.6 per $\mathrm{km}^{2}(\mathrm{SD}=1.8)$. In the facility density map (Fig. 3a), there is only one census tract that coincides with the top 10 census tracts in the carcinogen TEP score map (Fig. 3c), and only two census tracts that coincide with the top 10 census tracts in the noncarcinogenic TEP score map (Fig. 3d). In particular we note that the cluster of top 10 census tracts in

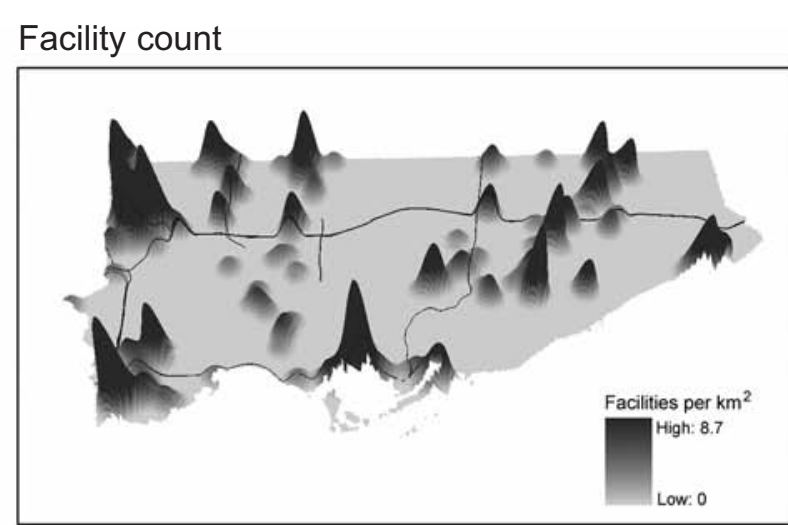

TEP score (carcinogens)

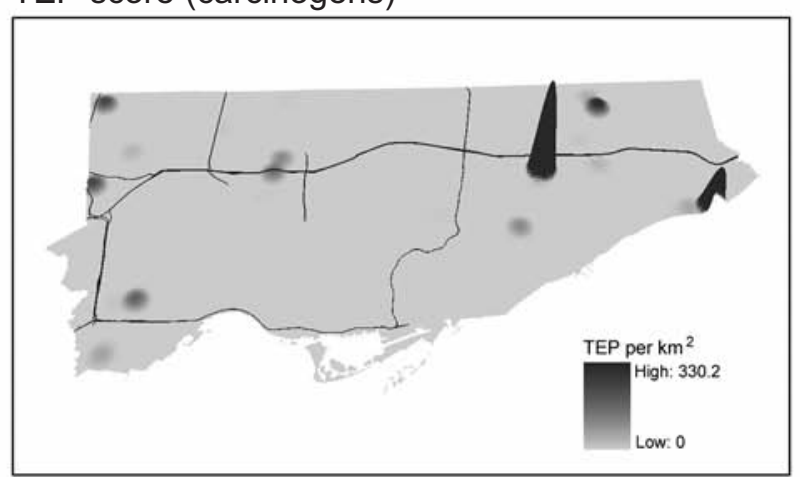

\section{Mass}

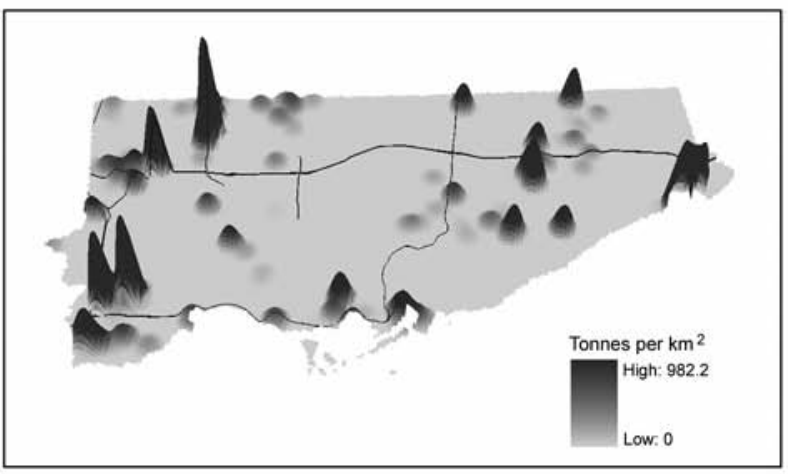

TEP score (non-carcinogens)

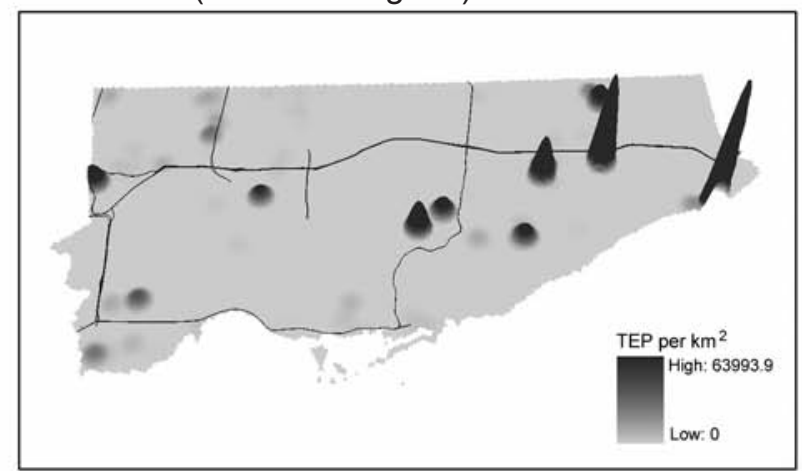

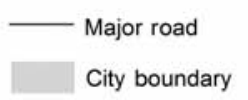

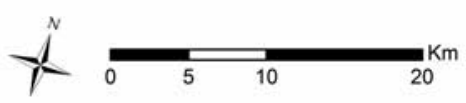

Fig. 2. Three-dimensional representation of kernel density estimation for facility count, mass of emissions and toxicity of emissions across the City of Toronto. 


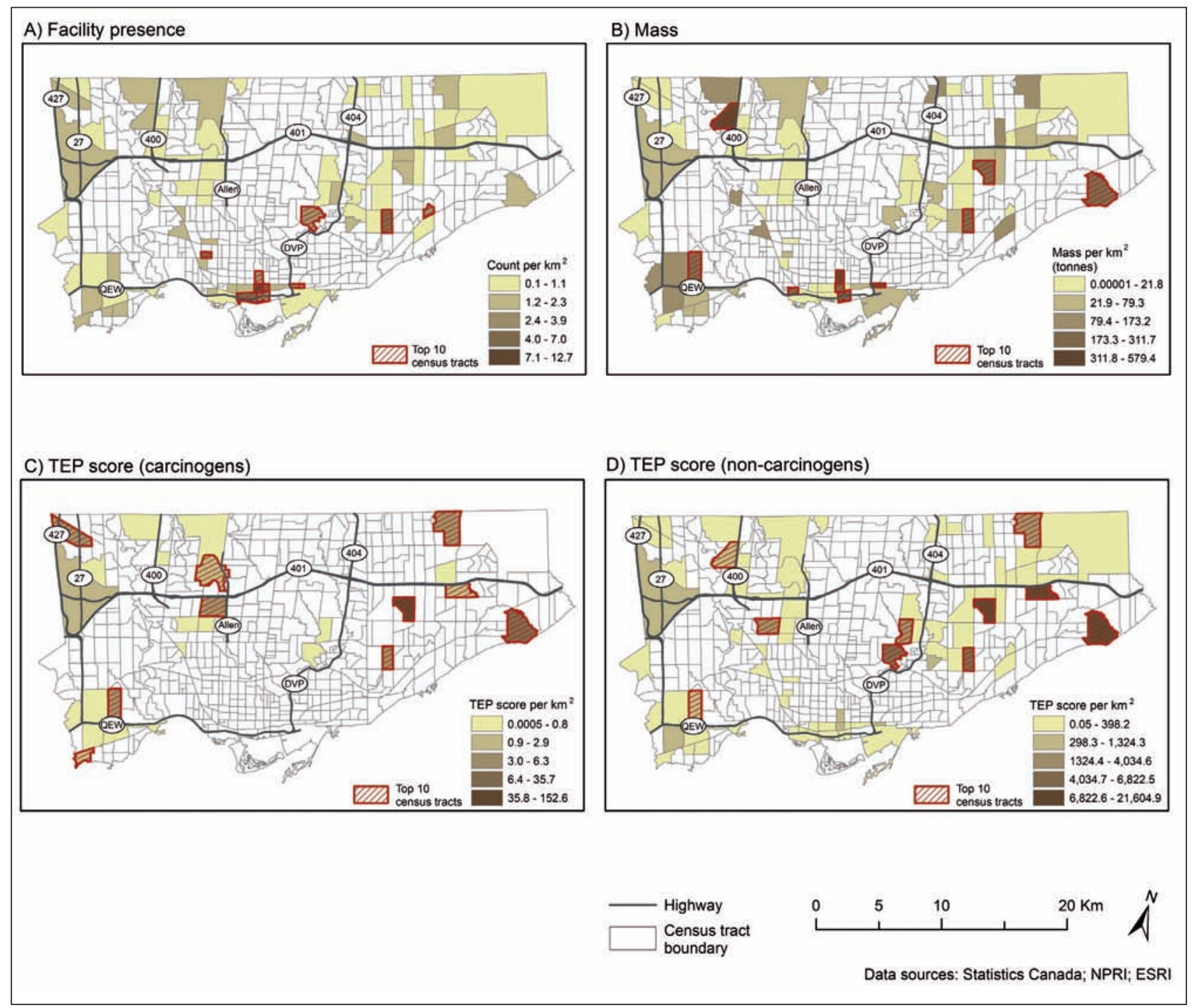

Fig. 3. (A) NPRI facility density; (B) mass of emissions in tonnes per $\mathrm{km}^{2}$; (C) TEP score per $\mathrm{km}^{2}$ (carcinogens); (D) TEP score per $\mathrm{km}^{2}$ (non-carcinogens), aggregated to the census tract level using the unit-hazard approach. Census tracts represented by cross-hatches contain the 10 highest values, while unshaded census tracts do not contain an NPRI facility.

Toronto's downtown core that have a high density of facilities (Fig. 3a) and mass of emissions per $\mathrm{km}^{2}$ (Fig. $3 \mathrm{~b}$ ) are not highlighted when the toxicity density of releases is considered (Figs. $3 \mathrm{c}$ and $3 \mathrm{~d}$ ).

Comparing socio-economic status of host and nonbost census tracts

When host census tracts defined by the unit-hazard approach were compared to non-host tracts, a significantly higher proportion of visible minorities $(+8.1 \%)$ were found in host tracts $(\mathrm{P}=0.006)$. Socio-economic status, represented by the proportion of individual incomes below the after-tax low-income cut-off (LICO), was virtually equal in host $(18.3 \%)$ and nonhost census tracts $(18.6 \%)$ (see Table 2 ).
When the distance-based approach was applied using a $1 \mathrm{~km}$ buffer, the visible minority, low income and low educational attainment indicators were all significantly higher $(\mathrm{P}<0.05)$ in host census tracts. Disparities among all demographic and socio-economic variables increased when the $2 \mathrm{~km}$ buffer was applied (see Table 2). Residential population with visible minority status averaged $49.5 \%$ within $2 \mathrm{~km}$ of an NPRI facility, compared to $33.4 \%$ elsewhere $(t(521)=$ $7.2, \mathrm{P}<0.001$ ), while the low-income rate was $5.1 \%$ higher in host tracts $(t(522)=6.0, \mathrm{P}<0.001)$. The percentage of recent immigrants, people not speaking English, those with low educational attainment, rented dwellings and those unemployed were also significantly higher $(\mathrm{P}<0.05)$ in host tracts using a $2 \mathrm{~km}$ buffer. 
Table 2. Socio-economic status in host and non-host census tracts using the unit-hazard and distance-based approaches (values in parentheses indicate standard deviation).

\begin{tabular}{|c|c|c|c|c|c|c|c|c|c|}
\hline \multirow[b]{2}{*}{ Variable } & \multicolumn{3}{|c|}{ Unit-hazard approach } & \multicolumn{3}{|c|}{ Distance-based approach $(1 \mathrm{~km})$} & \multicolumn{3}{|c|}{ Distance-based approach $(2 \mathrm{~km})$} \\
\hline & $\begin{array}{l}\text { Host } \\
\text { CTs }\end{array}$ & $\begin{array}{c}\text { Non-host } \\
\text { CTs }\end{array}$ & $\mathrm{P}$ & $\begin{array}{l}\text { Host } \\
\text { CTs }\end{array}$ & $\begin{array}{c}\text { Non-host } \\
\text { CTs }\end{array}$ & $\mathrm{P}$ & $\begin{array}{l}\text { Host } \\
\text { CTs }\end{array}$ & $\begin{array}{c}\text { Non-host } \\
\text { CTs }\end{array}$ & $\mathrm{P}$ \\
\hline Census tracts (count) & 72 & 455 & - & 151 & 376 & - & 362 & 165 & - \\
\hline Population (count in 1,000 s) & 365 & 2,130 & - & 710 & 1,785 & - & 1,694 & 802 & - \\
\hline \multicolumn{10}{|l|}{ Ethnicity/immigration/ language } \\
\hline Visible minority & $51.4(22.2)$ & $43.3(25.3)$ & $0.006^{*}$ & $50.1(22.5)$ & $42.2(25.7)$ & $<0.001 *$ & $49.5(24.2)$ & $33.4(23.4)$ & $<0.001^{*}$ \\
\hline Chinese & $10.9(12.9)$ & $11.2(15.1)$ & $0.851^{\mathrm{a}}$ & $12.3(16.1)$ & $10.7(14.3)$ & $0.194^{a}$ & $12.2(16.3)$ & $8.9(10.7)$ & $0.023^{* a}$ \\
\hline South Asian & $15.1(13.7)$ & $10.3(12.0)$ & $<0.001^{* a}$ & $12.7(12.8)$ & $10.2(12.1)$ & $0.005^{* a}$ & $12.5(12.7)$ & $7.5(10.9)$ & $<0.001^{* a}$ \\
\hline Black & $9.2(6.6)$ & $7.9(8.3)$ & $0.011^{\text {*a }}$ & $9.3(7.5)$ & $7.6(8.2)$ & $<0.001^{\text {*a }}$ & $9.3(8.5)$ & $5.4(6.4)$ & $<0.001^{\text {*a }}$ \\
\hline Filipino & $4.8(3.3)$ & $3.8(4.1)$ & $0.001^{* a}$ & $4.4(4.4)$ & $3.7(3.8)$ & $0.040^{* a}$ & $4.2(4.1)$ & $3.2(3.6)$ & $0.001^{a}$ \\
\hline White & $48.5(22.2)$ & $56.7(25.3)$ & $0.005^{*}$ & $49.9(22.5)$ & $57.8(25.7)$ & $<0.001 *$ & $50.5(24.2)$ & $66.6(23.4)$ & $<0.001 *$ \\
\hline Recent immigrant & $10.0(6.4)$ & $10.0(7.8)$ & $0.464^{a}$ & $10.3(6.3)$ & $9.9(8.1)$ & $0.083^{\mathrm{a}}$ & $11.1(7.8)$ & $7.7(6.8)$ & $<0.001^{* a}$ \\
\hline Not speaking English & $5.5(4.0)$ & $5.2(4.7)$ & $0.278^{\mathrm{a}}$ & $6.1(4.7)$ & $4.8(4.5)$ & $<0.001^{* a}$ & $6.2(4.9)$ & $3.0(2.7)$ & $<0.001^{* a}$ \\
\hline \multicolumn{10}{|l|}{ Income/education } \\
\hline Low income persons & $18.3(7.9)$ & $18.6(9.6)$ & 0.735 & $20.4(9.0)$ & $17.9(9.4)$ & $0.006^{*}$ & $20.2(9.4)$ & $15.1(8.2)$ & $<0.001 *$ \\
\hline Low educational attainment & $20.4(10.4)$ & $17.7(10.4)$ & $0.040 *$ & $21.4(10.9)$ & $16.8(10.0)$ & $<0.001^{*}$ & $20.8(10.4)$ & $12.1(7.7)$ & $<0.001 *$ \\
\hline \multicolumn{10}{|l|}{ Home ownership } \\
\hline Rented dwellings & $39.8(19.3)$ & $42.5(23.4)$ & 0.290 & $43.4(21.3)$ & $41.6(23.5)$ & 0.410 & $44.0(23.0)$ & $38.1(22.1)$ & $0.006^{*}$ \\
\hline \multicolumn{10}{|l|}{ Higher-risk populations } \\
\hline Children (<14 years) & $15.7(5.0)$ & $16.3(5.0)$ & 0.330 & $15.6(5.2)$ & $16.4(14.9)$ & 0.092 & $16.4(5.2)$ & $15.9(4.7)$ & 0.330 \\
\hline Seniors ( $\geq 65$ years) & $13.8(6.3)$ & $14.6(6.1)$ & $0.209^{\mathrm{a}}$ & $13.7(5.9)$ & $14.8(6.2)$ & $0.026^{* a}$ & $14.3(6.5)$ & $14.8(5.3)$ & $0.230^{\mathrm{a}}$ \\
\hline \multicolumn{10}{|l|}{ Employment } \\
\hline Unemployed & $7.7(2.7)$ & $7.6(2.7)$ & 0.781 & $7.9(2.7)$ & $7.5(2.7)$ & $\begin{array}{l}0.184 \\
0.179\end{array}$ & $8.0(2.8)$ & $6.7(2.4)$ & $<0.001^{* a}$ \\
\hline Management occupation & $9.3(4.7)$ & $10.9(5.6)$ & $0.009^{*}$ & $9.1(4.3)$ & $11.3(5.8)$ & $<0.001 *$ & $9.1(4.5)$ & $14.2(6.0)$ & $<0.001 *$ \\
\hline Business/admin. occupation & $20.7(4.2)$ & $19.9(3.8)$ & 0.116 & $20.0(4.2)$ & $20.1(3.7)$ & 0.806 & $19.8(4.0)$ & $20.6(3.5)$ & $0.023^{*}$ \\
\hline Trade occupation & $11.7(5.9)$ & $9.9(5.7)$ & $0.015^{*}$ & $11.8(6.1)$ & $9.6(5.5)$ & $<0.001^{*}$ & $11.6(5.7)$ & $7.1(4.6)$ & $<0.001 *$ \\
\hline Sales occupation & $22.9(5.6)$ & $22.1(4.9)$ & 0.216 & $23.1(4.7)$ & $21.9(5.1)$ & $0.017^{*}$ & $23.4(4.7)$ & $19.9(4.8)$ & $<0.001 *$ \\
\hline
\end{tabular}

*Significant at the $95 \%$ confidence level; ${ }^{a}$-test calculated using transformed variable.

Comparing census tracts within $2 \mathrm{~km}$ of the highest emitters to all other host tracts

The population characteristics of census tracts within a $2 \mathrm{~km}$ radius of the 10 largest emitters by mass and by TEP score were compared to census tracts within a $2 \mathrm{~km}$ radius of all other NPRI facilities (Table 3). The visible minority and low educational attainment variables were significantly higher (by $10.9 \%$ and $5.7 \%$, respectively, $\mathrm{P}<0.05$ ) in census tracts within $2 \mathrm{~km}$ of the 10 highest emitters by mass, while management occupation was significantly lower by $2.3 \%(t(72)=$ 4.1, $\mathrm{P}<0.001)$.

The Filipino $(+3.0 \%, \mathrm{t}(142)=3.9, \mathrm{P}<0.001)$ and business occupation $(+1.9 \%, t(142)=2.9, \mathrm{P}=0.004)$ variables were the only two indictors with significantly higher percentages among host tracts for the top 10 facilities by carcinogen TEP score compared to census tracts within $2 \mathrm{~km}$ of all other NPRI facilities releasing carcinogenic substances, while the low-income variable was significantly higher among non-host census tracts $(+3.1 \%, t(104)=2.1, P=0.04)$. However, the proportion of visible minority residents was $12.9 \%$ higher $(t(352)=3.5, P<0.001)$ in census tracts that are located within $2 \mathrm{~km}$ of the 10 most toxic facilities by noncarcinogenic TEP score compared to the proportion of visible minorities living within $2 \mathrm{~km}$ of all other host census tracts. The presence of South Asians and Filipinos was $12.2 \%(\mathrm{t}(50)=4.6, \mathrm{P}<0.001)$ and $1.7 \%$ $(\mathrm{t}(352)=2.9 \mathrm{P}=0.004)$ greater in the 10 most toxic 
Table 3. Comparison of socio-economic status of census tracts within $2 \mathrm{~km}$ of the top 10 emitters versus all other host census tracts (values in parentheses indicate standard deviation).

\begin{tabular}{|c|c|c|c|c|c|c|c|c|c|}
\hline \multirow[b]{2}{*}{ Variable } & \multicolumn{3}{|c|}{ Mass } & \multicolumn{3}{|c|}{ Toxicity (carcinogens) } & \multicolumn{3}{|c|}{ Toxicity (non-carcinogens) } \\
\hline & $\begin{array}{c}\text { Top } 10 \\
\text { facilities }\end{array}$ & $\begin{array}{l}\text { All other } \\
\text { facilities }\end{array}$ & $\mathrm{P}$ & $\begin{array}{c}\text { Top } 10 \\
\text { facilities }\end{array}$ & $\begin{array}{l}\text { All other } \\
\text { facilities }\end{array}$ & $\mathrm{P}$ & $\begin{array}{c}\text { Top } 10 \\
\text { facilities }\end{array}$ & $\begin{array}{l}\text { All other } \\
\text { facilities }\end{array}$ & $\mathrm{P}$ \\
\hline Census tracts (count) & 46 & 316 & - & 40 & 106 & - & 46 & 312 & - \\
\hline Population (count in 1,000 s) & 230 & 1,463 & - & 202 & 482 & - & 249 & 1,442 & - \\
\hline \multicolumn{10}{|l|}{ Ethnicity/immigration/language } \\
\hline Visible minority & $59.0(26.4)$ & $48.1(23.6)$ & $0.011 *$ & $55.1(24.0)$ & $52.8(25.6)$ & 0.618 & $60.4(23.6)$ & $47.5(23.7)$ & $<0.001^{*}$ \\
\hline Chinese & $10.5(16.2)$ & $12.4(16.3)$ & $0.273^{\mathrm{a}}$ & $10.2(14.3)$ & $8.0(13.3)$ & $0.327^{\mathrm{a}}$ & $11.5(15.1)$ & $12.4(16.5)$ & $0.711^{\mathrm{a}}$ \\
\hline South Asian & $16.1(11.1)$ & $12.0(12.8)$ & $0.005^{* a}$ & $17.6(13.6)$ & $16.2(15.4)$ & $0.401^{\mathrm{a}}$ & $22.9(17.5)$ & $10.7(10.5)$ & $<0.001^{\text {*a }}$ \\
\hline Black & $13.5(10.8)$ & $8.7(7.9)$ & $0.009^{* a}$ & $10.2(6.7)$ & $10.9(9.3)$ & $0.828^{\mathrm{a}}$ & $9.3(8.7)$ & $9.2(8.3)$ & $0.776^{\mathrm{a}}$ \\
\hline Filipino & $3.2(2.4)$ & $4.4(4.3)$ & $0.077^{\mathrm{a}}$ & $7.2(5.1)$ & $4.2(4.1)$ & $<0.001^{\text {*a }}$ & $5.7(4.9)$ & $4.0(4.0)$ & $0.004^{* a}$ \\
\hline White & $41.0(26.4)$ & $51.9(23.6)$ & $0.011 *$ & $44.9(24.0)$ & $47.2(25.6)$ & 0.616 & $39.6(23.6)$ & 52.5 & 0.001 \\
\hline Recent immigrant & $10.9(5.7)$ & $11.1(8.1)$ & $0.666^{a}$ & $10.5(5.8)$ & $12.2(9.0)$ & $0.446^{\mathrm{a}}$ & $14.3(10.0)$ & $10.5(7.2)$ & $0.003^{* a}$ \\
\hline Not speaking English & $6.8(4.6)$ & $6.1(4.9)$ & $0.166^{\mathrm{a}}$ & $5.6(4.4)$ & $6.3(4.1)$ & $0.367^{\mathrm{a}}$ & $6.1(4.3)$ & $6.2(5.0)$ & $0.964^{a}$ \\
\hline \multicolumn{10}{|l|}{ Income/education } \\
\hline Low income persons & $20.4(9.1)$ & $20.2(9.4)$ & 0.883 & $16.9(7.0)$ & $20.0(10.3)$ & $0.040 *$ & $21.0(10.7)$ & 20.0 & 0.506 \\
\hline Low educational attainment & $25.8(9.1)$ & $20.1(10.4)$ & $<0.001^{*}$ & $22.2(6.3)$ & $25.1(11.3)$ & 0.060 & $19.8(9.0)$ & $20.9(10.6)$ & 0.500 \\
\hline \multicolumn{10}{|l|}{ Home ownership } \\
\hline Rented dwellings & $39.2(21.7)$ & $44.7(23.2)$ & 0.133 & $36.7(19.9)$ & $42.7(23.8)$ & 0.161 & $45.5(26.7)$ & $43.6(22.5)$ & 0.611 \\
\hline \multicolumn{10}{|l|}{ Higher-risk populations } \\
\hline Children ( $<14$ years) & $19.3(4.7)$ & $15.9(5.1)$ & $<0.001^{*}$ & $17.7(3.1)$ & $18.6(4.8)$ & 0.311 & $19.0(4.7)$ & $15.9(5.0)$ & $<0.001^{*}$ \\
\hline Seniors ( $\geq 65$ years) & $14.4(4.7)$ & $14.3(6.7)$ & $0.703^{a}$ & $15.0(5.5)$ & $15.1(8.2)$ & $0.863^{a}$ & $14.9(6.0)$ & $14.3(6.6)$ & $0.497^{a}$ \\
\hline \multicolumn{10}{|l|}{ Employment } \\
\hline Unemployed & $8.6(2.6)$ & $7.9(2.8)$ & 0.130 & $7.8(2.6)$ & $8.3(3.1)$ & 0.296 & $8.3(3.2)$ & $8.0(2.7)$ & 0.466 \\
\hline Management occupation & $7.1(3.3)$ & $9.4(4.5)$ & $<0.001^{*}$ & $7.7(3.5)$ & $7.8(4.2)$ & $0.903^{\mathrm{a}}$ & $8.6(4.4)$ & $9.3(4.5)$ & $0.344^{\mathrm{a}}$ \\
\hline Business/admin. occupation & $19.7(4.1)$ & $19.8(4.0)$ & 0.870 & $21.6(3.0)$ & $19.7(3.5)$ & $0.004 *$ & $21.1(3.0)$ & $19.6(4.1)$ & $0.004 *$ \\
\hline Trade occupation & $14.7(4.1)$ & $11.2(5.7)$ & $<0.001^{*}$ & $13.0(3.7)$ & $14.6(5.9)$ & 0.051 & $11.5(4.6)$ & $11.6(5.8)$ & 0.905 \\
\hline Sales occupation & $23.3(3.1)$ & $23.4(4.9)$ & 0.945 & $24.7(4.9)$ & $23.7(4.1)$ & $0.237^{\mathrm{a}}$ & $23.5(4.2)$ & $23.3(4.8)$ & 0.877 \\
\hline
\end{tabular}

"Significant at the $95 \%$ confidence level; ${ }^{a} t$-test calculated using transformed variable.

host census tracts by non-carcinogenic TEP score respectively, compared to the percentage living within 2 $\mathrm{km}$ of all other host tracts. The proportion of recent immigrants and children was also significantly higher ( $\mathrm{P}$ $<0.05$ ) in the most toxic non-carcinogenic host tracts.

Neither low-income status, non-English speaking people, rented dwellings, seniors or unemployment were significantly higher in census tracts with the most toxic facilities or facilities emitting the greatest mass of emissions, as compared to other host tracts.

\section{Identifying census tracts with a double burden}

To identify areas in Toronto that may experience a double burden of toxic emissions and a high proportion of populations facing inequities, we identified the host tracts by the distance-based approach $(2 \mathrm{~km}$ buffers) around the five most toxic facilities by car- cinogen and non-carcinogen TEP score, and overlaid census tracts in the highest quintiles for the visible minority and low-income indicators.

One facility was in the top five by TEP score for both carcinogenic and non-carcinogenic substances. Five of the nine most toxic facilities identified in Fig. 4 (facilities C, D, E, F and G) are within $2 \mathrm{~km}$ of census tracts where high proportions of visible minorities and low-income persons coincide; these census tracts are represented by both shading and crosshatches (Fig. 4). Facilities A and B in the northwest part of the city and facility $\mathrm{H}$ in the northeast are located within $2 \mathrm{~km}$ of census tracts in the highest quintile by visible minority status, however these are not identified as low-income areas, and thus do not meet the "double burden" criterion. Facility I is not located in proximity to high values of either of the indicators of socio-economic burden. 


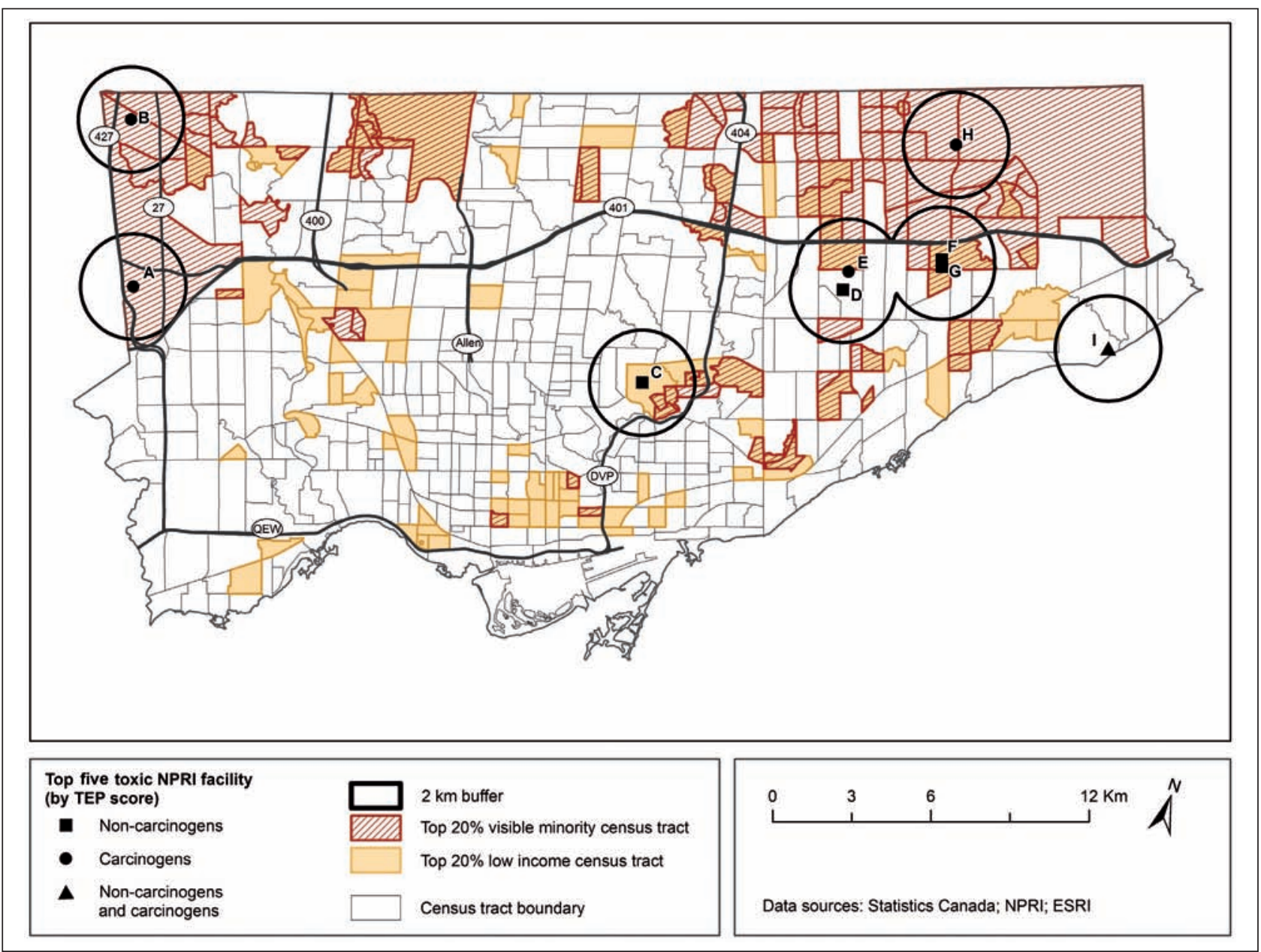

Fig. 4. The top five toxic facilities by carcinogen and by non-carcinogen TEP scores, respectively, are mapped with $2 \mathrm{~km}$ buffers. Census tracts with the cross-hatches are in the top quintile for visible minority presence, while census tracts shaded in orange are in the top quintile for low income.

\section{Discussion}

\section{Inequitable exposure to toxic air pollution}

Our findings show that there are issues of environmental injustice in the City of Toronto with respect to the location, mass and toxicity of industrial sources of air pollution. "Racialized" communities and neighbourhoods with low socio-economic status are often located in proximity to NPRI facilities. Furthermore, "racialized" communities are disproportionately located near facilities that release both large quantities and the most harmful pollutants. We note in particular the results related to "racialization", which have not been found in Toronto before. The disparities are greatest when considering facilities emitting non-carcinogenic substances, where the average visible minority population is $60.4 \%$ within $2 \mathrm{~km}$ of a top- 10 facility compared to $47.5 \%$ within $2 \mathrm{~km}$ of all other facilities. When considering the four largest visible minor- ity groups in Toronto by population, the South Asian and Filipino populations have significantly higher percentages of being located within $2 \mathrm{~km}$ of NPRI facilities emitting the most toxic non-carcinogenic substances.

Environmental justice studies based in the USA have also found a higher proportion of minorities near hazardous facilities (Ash and Fetter, 2004; Pastor et al., 2004), which supports the notion posited by Buzzelli and Jerrett (2004) that "environmental racism" may be a more appropriate term than environmental justice to describe disparities. This is despite the fact that residential segregation is not found to the same degree in Canadian urban areas as it is in the USA (Walks and Bourne, 2006).

This study emphasises the importance of including measures of toxicity when developing pollution prevention strategies. The toxicological characteristics of emissions affect the health risk posed by large industrial facilities, thus influencing priority locations for 
public health policy. Public health efforts are focused on improving the health of the whole population and on reducing health inequalities. Evidence suggests that those facing inequities are already at higher risk of adverse health outcomes. Our approach of mapping the most toxic facilities with census tracts in the highest quintile by low income and visible minority status offers a way to locate where those inequities are compounded by potentially harmful exposures. By focusing efforts on areas that are most vulnerable, inequities are reduced and pollution exposure is minimised.

Many environmental justice studies do not consider exposure to pollutants but are limited to the locations of hazardous facilities (Sheppard et al., 1999; Saha and Mohai, 2005; Kearney and Kiros, 2009). Those studies assume that distance from an emission source is a reliable proxy for human exposure (Jerrett et al., 2005). Such proximity analysis does not consider the relative amounts of various substances emitted, their fate and transport characteristic or their toxicological properties.

Land use patterns and housing affordability are two converging factors that may help explain why individuals with low socio-economic status are differentially exposed to the potential health impacts of large industrial facilities (Crouse et al., 2009). Poorer individuals from segregated minority groups may be doubly disadvantaged in the housing market and may be forced to reside in the most disadvantaged neighbourhoods (Fong and Shibuya, 2000). Furthermore, there is a greater propensity for "racialized" neighbourhoods to experience higher unemployment and low income rates than other neighbourhoods (Hou and Picot, 2003), although this may be because approximately one third of "racialized" groups are recent immigrants (Hou and Picot, 2004).

\section{Limitations}

This study is not without limitations. Although we used two different approaches to defining host tracts, and the distance-based approach also used two different buffer distances, all of these variants still include dramatic simplifications of potential human exposure. For example, directional effects of air pollution due to weather and climate, the effect of stack height, or the temporal patterns of releases are not taken into account. Other parameters in the analysis tools could also influence the outcomes of this research. Specifically, the selection of different administrative boundaries, socio-economic variables or different thresholds for the greatest polluters could yield dis- tinct associations between air pollution and population characteristics.

We also have to acknowledge that air pollution from large industrial sources represents only a fraction of all air pollutants across the City of Toronto. Emissions from residential homes, small and medium businesses, mobile and trans-boundary sources also contribute to ambient levels of air pollution. While environmental justice research in the past has been primarily concerned with industrial air pollution sources, there is a growing consensus that all point and mobile sources should be included in future studies (Maantay, 2002; Pastor et al., 2005), especially in light of the importance being placed on assessing the effects of cumulative exposure to multiple pollutants.

\section{Conclusions and outlook}

The objective of this study was to explore whether residential proximity to large industrial air pollution sources in the City of Toronto emitting the most toxic substances is associated with low socio-economic or minority status. Considering both mass and toxicity of emissions as well as social and economic inequities, we were able to characterise neighbourhoods which are exposed to the most harmful industrial airborne emissions. Given the limited affordable housing choices available to lower income groups in large cities such as Toronto, it is vital to protect the population from exposure to toxic substances wherever they live. By explicitly addressing vulnerable populations, these results support effective and equitable priority setting for pollution prevention.

The City of Toronto's ChemTRAC programme, which requires small and medium businesses in Toronto to report air releases of 25 priority substances as of 2010 (Toronto Public Health, 2009), will supplement data collected by the NPRI to provide more comprehensive information regarding the distribution of air pollution sources across Toronto. In the context of the ChemTRAC programme, the analysis presented in this study will also provide Toronto Public Health with an indication of areas in Toronto where pollution prevention strategies may be prioritised.

While the relationship between distance to an NPRI facility in the City of Toronto and actual exposure to pollution remains unknown, there are other negative impacts common to neighbourhoods surrounding industrial facilities including noise, traffic, contaminated soil, odours, fewer amenities and poorer quality housing (Perlin et al., 1999). Population health approaches suggest that health is based on complex 
interactions among many factors. The type of analysis presented here, which combines potential exposure and increased vulnerability, is one step towards understanding the extent to which health is linked either directly or indirectly to living near an industrial facility in a major city.

\section{Acknowledgements}

Helpful comments on this research and on earlier versions of the manuscript by Donald Cole, Loren Vanderlinden, Ronald Macfarlane, Nancy Day, Marco Belmont, Christopher Morgan and Sean Severin are gratefully acknowledged. Jadah FolliottArokium assisted with the final manuscript preparation.

\section{References}

Abel TD, 2008. Skewed riskscapes and environmental injustice: a case study of metropolitan St. Louis. Environ Management 42, 232-248.

Allen DW, 2001. Social class, race and toxic releases in American countries, 1995. Soc Sci J 38, 13-25.

Anderson T, 2009. Kernel density estimation and k-means clustering to profile road accident hotspots. Accident Analys Prev 41, 359-364.

Ash M, Boyce J, Chang G, Pastor M, Scoggins J, Tran J, 2009. Justice in the air: tracking toxic pollution from America's industries and companies to our states, cities, and neighborhoods. Political Economy Research Institute. Available at: http://dornsife.usc.edu/pere/documents/justice_in_the_air_we b.pdf (accessed on May 2013).

Ash M, Fetter TR, 2004. Who lives on the wrong side of the environmental tracks? Evidence from the EPA's risk-screening environmental indicators model. Soc Sci Q 85, 441-462.

Bauder H, 2001. Visible minorities and urban analysis. Can J Urban Res 10, 69-90.

Benjamin F, Lee CC, 1987. Toxic wastes and race in the United States: a national report on the racial and socioeconomic characteristics of communities with hazardous waste sites. Report, United Church of Christ Commission for Racial Justice.

Brunekreef B, Holgate S, 2002. Air pollution and Health. Lancet 360, 1233-1242.

Buzzelli M, 2008. Environmental Justice in Canada - It matters where you live. Canadian Policy Research Networks, Report. Available at: http://www.cprn.org/documents/50875_EN.pdf (accessed on May 2010).

Buzzelli M, Jerrett M, 2004. Racial gradients of ambient air pollution exposure in Hamilton, Canada. Environ Plan A 36, 1855-1876.

Caldwell J, Woodruff, TJ, Morello-Frosch R, Axelrad DA, 1998. Application of health information to hazardous air pol- lutants modeled in EPA's cumulative exposure project. Toxicol Ind Health 14, 429-454.

Chakraborty J, Armstrong MP, 1997. Exploring the use of buffer analysis for the identification of impacted areas in environmental equity assessment. Cartography Geograph Inf Sci 24, 145-157.

Cohen AJ, 2000. Outdoor air pollution and lung cancer. Environ Health Persp 108, 743-750.

Commission on Systemic Racism in the Ontario Criminal Justice System, 1995. Report of the Commission on Systemic Racism in the Ontario Criminal Justice System. Toronto: Queen's Printer for Ontario.

Corcoran J, Higgs G, Brunsdon C, Ware A, 2007. The use of comaps to explore the spatial and temporal dynamics of fire incidents: a case study in South Wales, United Kingdom. Profess Geograph 59, 521-536

Crouse DL, Ross NA, Goldberg MS, 2009. Double burden of deprivation and high concentrations of ambient air pollution at the neighbourhood scale in Montreal, Canada. Soc Sci Med 69, 971-981.

$\mathrm{CSDH}, 2008$. Closing the gap in a generation: health equity through action on the social determinants of health. Final Report of the Commission on Social Determinants of Health. Geneva: World Health Organization.

Daniels G, Friedman S, 1999. Spatial inequality and the distribution of industrial toxic releases: evidence from the 1990 TRI. Soc Sci Quart 80, 244.

Dockery DW, Pope CA, Xu X, Spengler JD, Ware JH, Fay ME, Ferris BG, Speizer FE, 1993. An association between air pollution and mortality in six U.S. cities. N Engl J Med 329, 1753-1759.

Environment Canada, 2009. Summary of NPRI reporting requirements for 2009. Gatineau (QC): Government of Canada. Available at: http://www.ec.gc.ca/inrp-npri/default.asp?lang= En\&n=D144BC2F (accessed on March 2010).

Environment Canada, 2010. National pollutant release inventory. Gatineau (QC): Government of Canada. Available at: http:// www.ec.gc.ca/inrp-npri/default.asp?lang=En\&n=4A577BB9 (accessed on May 2010).

Filion, P, 1991. The gentrification-social structure dialectic: a Toronto case study. Int J Urb Reg Res 15, 553-574.

Fong E, Shibuya K, 2000. The spatial separation of the poor in Canadian cities. Demography 37, 449-459.

Fotheringham S, Brunsdown C, Charlton M, 2000. Quantitative geography: perspectives on spatial data analysis. Thousand Oaks, CA: Sage.

Goldman B, Fitton L, 1994. Toxics wastes and race revisited. Center for Policy Alternatives, Washington (DC): Center for Policy Alternatives.

Hertwich EG, Mateles SF, Pease WS, McKone TE, 2001. Human toxicity potentials for life cycle assessment and Toxics Release Inventory risk screening. Environmental 
Toxicology and Chemistry 20, 928-939.

Hipp J, Lakon C, 2010. Social disparities in health: disproportionate toxicity proximity in minority communities over a decade. Health Place 16, 674-683.

Hou F, Picot G, 2003. Visible minority neighbourhoods and labour market outcomes of immigrant. Ottawa $(\mathrm{ON})$ : Analytical Studies Branch research paper series, Statistics Canada Catalogue No. 11F0019MIE, no. 204.

Hou F, Picot G, 2004. Visible minority neighbourhoods in Toronto, Montreal, and Vancouver. Ottawa $(\mathrm{ON})$ : Statistics Canada Catalogue No. 11-008.

Hum D, Simpson W, 2000. Not all visible minorities face labour market discrimination. Policy Options/Options Politiques 21, 45-48.

Jerrett M, Burnett RT, Ma RJ, Pope CA, Krewski D, Newbold KB, Thurston G, Shi YL, Finkelstein N, Calle EE, Thun MJ, 2005. Spatial analysis of air pollution and mortality in Los Angeles. Epidemiology 16, 727-736.

Kearney G, Kiros GE, 2009. A spatial evaluation of socio demographics surrounding National Priorities List sites in Florida using a distance-based approach. Int J Health Geogr 8, 33-43.

Lillie-Blanton L, 1996. Race/ethnicity, the social environment, and health. Soc Sci Med 43, 83-91.

Maantay J, 2002. Mapping environmental injustices: pitfalls and potential of geographic information systems in assessing environmental health and equity. Environ Health Persp 110, 161-171.

Marmot M, Wilkinson RG, 2006. Social determinants of health. 2nd Edition. New York: Oxford University Press.

McKone T, 1993. CalTOX, a multimedia total exposure model for hazardous-waste sites. Washington (DC): U.S. Department of Energy, Lawrence Livermore National Laboratory, Government Printing Office.

Mohai P, Saha R, 2006. Reassessing racial and socioeconomic disparities in environmental justice research. Demography 43, 383-399.

National Research Council, 1994. Science and Judgement in Risk Assessment. Report of the Committee on Risk Assessment of Hazardous Air Pollutants. Washington, DC: National Academy Press.

Nazroo J, 2003. The structuring of ethnic inequalities in health: economic position, racial discrimination, and racism. Am J Pub Health 93, 277-284.

Neumann CM, Forman DL, Rothlein JE, 1998. Hazard screening of chemical releases and environmental equity analysis of populations proximate to toxic release inventory facilities in Oregon. Environ Health Persp 106, 217-226.

Nnorom O, 2011. Environmental racism research in Canada. Proceedings of the 3rd North American Congress of Epidemiology. Montreal (June 21-24, 2011).

Pastor M, Morello-Frosch R, Sadd JL, 2005. The air is always cleaner on the other side: race, space, and ambient air toxics exposures. Calif J Urb Affairs 27, 127-148.

Pastor M, Sadd JL, Morello-Frosch R, 2004. Waiting to inhale: The demographics of toxic air release facilities in 21st-century California. Soc Sci Q 85, 420-440.

Pennington DW, Bare JC, 2001. Comparison of chemical screening and ranking approaches: The waste minimization prioritization tool versus toxic equivalency potentials. Risk Analysis 21, 897-912.

Perlin SA, Sexton K, Wong DWS, 1999. An examination of race and poverty for populations living near industrial sources of air pollution. J Expo Sci Environ Epidemiol 9, 29-48.

Pope CA, Burnett RT, Thun MJ, Calle E, Krewski D, Ito K, Thurston GD, 2002. Lung cancer, cardiopulmonary mortality, and long-term exposure to fine particulate air pollution. JAMA 287, 1132-1141.

Rang S, de Leon F, Foulds J, Ginsburg, J, Waffle C, Mitchell K, Finnigan D, 2008. An examination of pollution and poverty in the Great Lakes Basin. Report dated November 2008, Canadian Environmental Law Association and Environmental Defence, Toronto, Canada. Available at: http://www.pollutionwatch.org/pub/pollutionandpoverty.jsp (accessed on May 2009).

Raphael D, 2004. Social determinants of health: Canadian perspectives. Toronto: Canadian Scholars' Press Inc.

Saha R, Mohai, P, 2005. Historical Context and Hazardous Waste Facility Siting: Understanding Temporal Patterns in Michigan. Social Problems 52, 618-648.

Samet J, Krewski D, 2007. Health effects associated with exposure to ambient air pollution. J Toxicol Environ Health 70, 227-242.

Samet JM, Dominici F, Curruero FC, Coursac I, Zeger S, 2000. Fine particulate air pollution and mortality in 20 U.S. cities, 1987-1994. N Engl J Med 343, 1742-1749.

Schwartz J, 1994. Air pollution and daily mortality: a review and meta-analysis. Environ Res 64, 36-52.

Sheppard E, Leitner H, McMaster RB, Tian HG, 1999. GISbased measures of environmental equity: Exploring their sensitivity and significance. J Expo Sci Environ Epidemiol 9, 18-28. Sicotte D, 2010. Some more polluted than others: unequal cumulative industrial hazard burdens in the Philadelphia MSA, USA. Local Environ 15,761-774.

Statistics Canada, 2010. Visible minority. Ottawa (ON): Government of Canada. Available at: http://www.statcan.gc.ca/ concepts/definitions/minority-minorite1-eng.htm (accessed on May 2010).

Toronto Public Health, 2002. Potential for occupational and environment exposure to ten carcinogens in Toronto. Available at: http://www.toronto.ca/health/cr_index.htm (accessed on July 2010).

Toronto Public Health, 2004. Air pollution burden of illness in Toronto. http://www.toronto.ca/health/hphe/pdf/air_and_ 
health_burden_illness.pdf (accessed on August 2009).

Toronto Public Health, 2008. The unequal city. Income and health inequalities in Toronto. http://www.toronto.ca/health/ map/pdf/unequalcity_20081016.pdf (accessed on May 2010).

Toronto Public Health, 2009. Environmental reporting and disclosure bylaw (municipal code chapter 423): Guide to reporting. Toronto $(\mathrm{ON})$ : City of Toronto. Available at: http://www.toronto.ca/chemtrac (accessed on May 2010).

United Nations Committee on the Elimination of Racial Discrimination, 2007. Concluding observations of the Committee on the Elimination of Racial Discrimination Canada. Geneva: Office of the United Nations High Commission on Human Rights. Available at: http:// www2.ohchr.org/english/bodies/cerd/cerds70.htm (accessed on May 2010).

US Environmental Protection Agency, 1997. Human exposure assessment: A guide to risk ranking, risk reduction and research planning. EPA/SAB/IAQC-95-005. Washington (DC): Government Printing Office.

US Environmental Protection Agency, 2012. Toxic air pollutants. Online information, last updated on June 21, 2012, US Environmental Protection Agency, Washington, DC, USA. Available at: http://www.epa.gov/air/toxicair/newtoxics.html (accessed on May 2013).

Wakefield S, Baxter J, 2010. Linking health inequality and environmental justice: articulating a precautionary framework for research and action. Environ Just 3, 95-102.

Walks R, Bourne L, 2006. Ghettos in Canada's cities? Racial segregation, ethnic enclaves and poverty concentration in Canadian urban areas. Canad Geograph 50, 273-297.

Wing M, Tynon J, 2006. Crime mapping and spatial analysis in national forests. J Forestry 104, 293-298. 